\title{
Nerve tube in peripheral nerve repair
}

\author{
Ceylon Medical Journal 2011; 56: 83-84
}

Primary nerve repair is the preferred method after a nerve transection. Properly timed repair using microsurgical techniques give good results. Conventional nerve graft is an autologous nerve graft. An autologous sensory nerve is usually used as there are few expendable motor nerves. Nerve graft is oriented in reverse fashion and multiple cables are used depending on the circumference of the injured nerve. Sural nerve is the commonly used autologous nerve graft. Sural nerve harvesting is always associated with donor site morbidity. Nerve transfers, end to side nerve repair, vascular grafts and muscle flaps are also used with variable outcome [1].

Nerve tube is an alternative. This is a biodegradable transparent tube which comes in different diameters. Technique of nerve repair is simple (Figure 1). After preparing the severed nerve ends, those are fed into a proper-sized nerve tube with fine non-absorbable sutures [2].

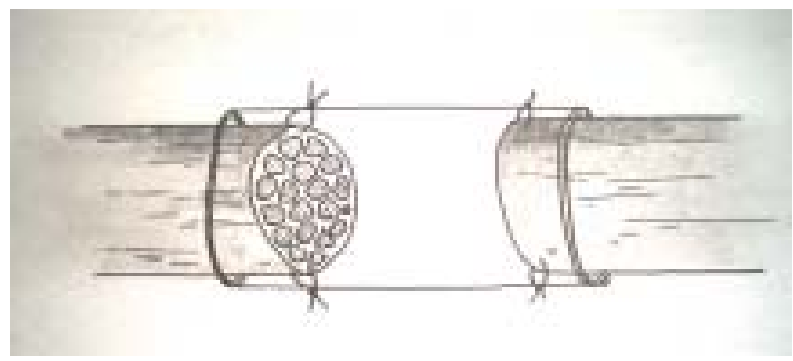

Figure 1. Tubular nerve graft

Compared to the conventional method nerve tube has no donor site morbidity and requires less operating time due to the simplicity of technique. Disadvantages are the cost of the nerve tube and inability to use for nerve gaps of more than $30 \mathrm{~mm}$ [3].

A 22-year old navy soldier presented with loss of sensation over radial aspect of his left index finger. This was after laceration over the radial side of his left palm 8 months ago. On examination he had a healed scar with positive Tinel's sign over it. A damaged digital nerve was suspected.

Exploration was done under general anaesthesia in a bloodless field. A $20 \mathrm{~mm}$ gap was found following preparation of nerve edges. Coaptation was done with a $100 \%$ synthetic (lactide-caprolactone polymeric material) nerve tube of $2 \mathrm{~mm}$ diameter and $30 \mathrm{~mm}$ in length. Edges were sutured with $7 / 0$ polypropylene and skin approximated with $5 / 0$ polypropylene. Patient was assessed regularly using progressive Tinel's sign, two point discrimination and monofilament sensory test.

Nerve tube is a good alternative to avoid donor site morbidity in peripheral nerve repair of short distance $(<$ $30 \mathrm{~mm}$ ). As the cost of the nerve tube is high, it is not a gain without a loss [4].

\section{References}

1. Dablin LB. Techniques of peripheral nerve repair. Scandinavian Journal of Surgery 2008; 97: 310-5.

2. Ichihara S, Inada Y, Nakamura T. Artificial nerve tubes and their application for repair of peripheral nerve injury. Injury 2008; 39: 29-39.

3. Inada Y, Marimoto S, Takakura F, et al. Regeneration of peripheral nerve gaps with a polyglycolic acid - collagen. Neurosurgery 2004; 55: 640-8. 
4. Rosberg HE, Carlsson KS, Hojgord S, Lindgren B, Lundbrog G, Dahlin LB. Injury to the human median and ulnar nerves in the forearm-analysis of 69 patients in southern Sweden. British Journal of Hand Surgery 2005; 30: 35-9.

\section{A Perera ${ }^{1}$, A S Ratnayake ${ }^{1}$, D A Dissanayake ${ }^{1}$}

${ }^{1}$ Plastic and Reconstructive Unit, National Hospital of Sri Lanka.

Correspondence: VAP, e-mail <vaperera@yahoo.com>. Received 12 May 2010 and revised version accepted 14 January 2011. 